\title{
Bloating Mechanism for Artificial Light Weight Aggregate of Surface Modification with Coal ash
}

\author{
Ki Gang Lee Le $^{\dagger}$ \\ Department of Advanced Materials Science and Engineering, Kyonggi University, Suwon 443-760, Korea \\ (Received December 3, 2014; Revised January 26, 2015; Accepted February 2, 2015)
}

\begin{abstract}
We manufacture artificial lightweight aggregates (ALWAs) using bottom-ash as the primary raw material. We coat the ALWA surfaces with low-melting point materials in order to enable them to bloat, which is essential to reduce the bulk density of the aggregate. Then, we sinter the prepared aggregates at 1000,1100 , and $1200^{\circ} \mathrm{C}$ using either the direct or two-step firing schedules. Finally, we evaluate the properties of the fired samples through analyzing their bulk density, water absorption, and microstructure. The surface-modified samples result in a reduction of their bulk density by $0.3 \sim 0.4 \mathrm{~g} / \mathrm{cm}^{3}$ regardless of the firing method used. Based on these results, we conclude that this approach could provide a viable method for the mass-production of ALWAs from industrial waste such as bottom-ash.
\end{abstract}

Key words : Lightweight aggregate, Bottom-ash, Bloating, Direct firing, Two-step firing

\section{Introduction}

A mong the total domestic consumption of electric power, approximately $37 \%$ is generated by thermal power plants. However, the process produces over 9 million tons of coal ash as a by-product as of year 2010. Only about 5.25 million tons of them are recycled. The rest, normally consisting of relatively coarse ash with high contents of carbon, are mostly discarded for land-reclamation. This causes problems to the thermal power plants since a rather high expense is needed for an additional construction and management of ash-treating pond.

More serious problem is the fact that the amount of discarded coal ash is increasing since there are more thermal power plants constructed every year. Thus, the coal ash recycling is a critical issue to be resolved. Consequently, research for the viable methods to reuse the waste becomes an urgent task to be investigated. ${ }^{1-5)}$

Domestically, various reports on the coal ash recycling and its feasibility study are available that include; for uses as a concrete admixture mainly utilizing the fly ash, as a filler material for road pavement, and as an aggregate for cement mortar replacing the smaller portion of aggregates. We have also involved in researches on the coal ash recycling, and recently, have extended our focus to the industrial wastes recycling especially for manufacturing of artificial lightweight aggregates (ALWA).

Various researches on the waste treatments include; the

${ }^{\dagger}$ Corresponding author : Ki Gang Lee

E-mail : gglee@kyunggi.ac.kr

Tel : +82-31-249-9762 Fax : +82-31-244-6300 property improvement of ALWA with the additions of flux$\mathrm{es}^{3)}$, the feasibility study for ALWA for concrete by utilizing industrial wastes ${ }^{4}$, the manufacturing method of ALWA using the reclaimed ash from thermal power plants ${ }^{6}$, the sintered properties of ALWA prepared from coal ash and limestone ${ }^{7)}$, etc. These studies contributed for the reuses of waste materials and established its technical methods. Despite all these efforts, the present status is still far from satisfactory.

Studies on the ALWA mainly focused on the reduction of aggregate's bulk density by bloating. The bloating mechanism involves in the oxidation of carbon followed by reduction of iron that generate gases for bloating. Lee ${ }^{1)}$ produced the ALWA by adding iron into the batch of mainly coal ash and pointed out that the bloating process was limited due to the cracks on the aggregate surface at the presence of $\mathrm{FeO}$ based melt phase.

Kang et $a l .^{2)}$ investigated the effects of various carbon sources and its contents on the generation of bloating gases for the ALWA by utilizing coal ash. They presented two difficult cases of achieving lightweight where the lesser contents of carbon resulted in insufficient generation of bloating gases and the excessive contents of carbon in unsatisfactory densification. Tsai et $a l^{3)}$ studied the bloating characteristics of ALWA from the recycled sludge in terms of $\mathrm{SiO}_{2}-\mathrm{Al}_{2} \mathrm{O}_{3}$-flux ratio and found that the properties of ALWA was difficult to predict due to the diversity of raw material in composition-wise.

This study involves in the manufacturing of ALWA from the coal ash for land-reclamation by employing the surface coating technique with low-melting materials such as slag, dredged-soil, and acidic clay. We sintered the coated aggregates via both direct and two-step firing schedules. We expected that 
the formation of surface melt layer at firing temperatures successfully trap bloating gases.

We investigated the properties of the foamed aggregates and analyzed the characteristics of bloating mechanism. We finally, based on the results, examined the feasibility of this approach to the mass production of ALWA.

\section{Experimental Procedure}

\subsection{Raw materials}

Coal ash, the main raw material, is the discharged bottom-ash from the combustion of bituminous coal in $\mathrm{Y}$ thermal power plant. Coating materials used for experiments are dredged-soil that occurred during the plant construction, slag from plasma-melting furnace, and acidic clay (Donghae Chemicals Ind. Co. Ltd., Korea). All raw materials were ground $<100 \mu \mathrm{m}$ using a pin mill. The chemical compositions of the ground raw materials were analyzed by XRF (ZSR- 100e, Rigaku, Japan) as shown in Table 1.

\subsection{Preparation and analysis of $A L W A$}

The preliminary samples were made of $100 \%$ of each raw materials alone (bottom-ash, dredged-soil, slag, or acidic clay) that was ground to $<100 \mu \mathrm{m}$ to evaluate their behaviors under firing. Based on the results from the preliminary samples, the mixed samples of bottom-ash and dredged-soil with the wt. ratio of $70: 30$ were prepared. The specific wt. ratio is based on the fact that bottom-ash itself has no plasticity and has not enough bloating capability at low temperatures due to its high refractoriness. Dredged-soil, however, can provides the necessary plasticity to bottom-ash and could contribute in lowering the refractoriness of the mixture.

All samples formed into the sphere-like shapes with diameters of about $10 \mathrm{~mm}$. In addition, to observe how each raw materials behave on the surface of aggregates, we coated the

Table 1. Chemical Compositions of Raw Materials

(wt\%)

\begin{tabular}{ccccc}
\hline & Bottom-ash & Dredged-soil & Slag & Acidic clay \\
\hline $\mathrm{SiO}_{2}$ & 60.82 & 70.05 & 48.61 & 56.74 \\
$\mathrm{Al}_{2} \mathrm{O}_{3}$ & 25.42 & 14.25 & 12.40 & 13.10 \\
$\mathrm{Fe}_{2} \mathrm{O}_{3}$ & 4.14 & 3.78 & 5.47 & 7.42 \\
$\mathrm{CaO}$ & 1.00 & 0.78 & 21.00 & 3.58 \\
$\mathrm{MgO}$ & 0.94 & 0.18 & 2.55 & 2.60 \\
$\mathrm{Na}_{2} \mathrm{O}$ & 0.08 & 2.4 & 0.620 & 1.98 \\
$\mathrm{~K}_{2} \mathrm{O}$ & 3.23 & 2.67 & 1.01 & 2.41 \\
$\mathrm{TiO}_{2}$ & 0.84 & 0.79 & 0.72 & 1.10 \\
$\mathrm{P}_{2} \mathrm{O}_{5}$ & 0.12 & 0.03 & 1.03 & 0.52 \\
$\mathrm{MnO}$ & 0.03 & 0.00 & 0.37 & 0.14 \\
$\mathrm{C}$ & 1.74 & 0.00 & 0.00 & 0.00 \\
$\mathrm{SO}_{3}$ & 0.43 & 0.00 & 0.00 & 0.00 \\
$\mathrm{Cr}_{2} \mathrm{O}_{3}$ & 0.00 & 0.00 & 0.69 & 0.00 \\
$\mathrm{Ig} \mathrm{loss}_{2}$ & 1.04 & 4.04 & 0.00 & 10.40 \\
$\mathrm{Total}$ & 100 & 100 & 100 & 100 \\
\hline
\end{tabular}

surfaces of the formed aggregates with about $5 \mathrm{wt} \%$ of flux materials such as slag, dredged-soil, or acidic clay. We, then, dried the coated samples in a dryer of $105^{\circ} \mathrm{C}$ for $24 \mathrm{~h}$. We selected two firing methods, a direct firing and a two-step firing, to modulate and optimize the escaping rate of bloating gases and the densification and vitrification rates of surface.

In the case of direct firing, we sintered at maximum temperatures of $1000^{\circ} \mathrm{C}, 1100^{\circ} \mathrm{C}$, and $1200^{\circ} \mathrm{C}$ for $10 \mathrm{~min}$ to minimize the loss of bloating gases. In the case of two-step firing, on the contrary, we first sintered at lower temperature of $900^{\circ} \mathrm{C}$ and increased the temperature up to $1150^{\circ} \mathrm{C}$ for the secondary sintering and surface vitrification. This procedure could provide the maximum generation of useful bloating gases and, at the same time, their escape out of aggregates could be minimized.

Three different schedules were adopted for the two-step firing; (I) $7 \mathrm{~min}$ at $900^{\circ} \mathrm{C}+3 \mathrm{~min}$ at $1150^{\circ} \mathrm{C}$, (II) $10.5 \mathrm{~min}$ at $900^{\circ} \mathrm{C}+4.5 \mathrm{~min}$ at $1150^{\circ} \mathrm{C}$, and (III) $14 \mathrm{~min}$ at $900^{\circ} \mathrm{C}+6 \mathrm{~min}$ at $1150^{\circ} \mathrm{C}$ as shown in Fig. 1. After firing, we measured bulk density and water absorption of each sample according to KS L 3114 standard. We also analyzed the microstructure of cross-sectional surfaces under the optical microscope (Camscope, DSC-105, Sometech, Korea) to observe the effects of coating materials, temperature, and firing methods.

\section{Results and Discussion}

\subsection{Melting behaviors of raw materials on surface}

ALWA achieves its low densities by bloating, and the bloating mechanism involves in generation of gases and their trapping inside of the aggregates. The organic matters and carbon included in raw materials can generate bloating gases by oxidation during firing. After a densified layer forms on the surface shell, no further oxidation will take place. Instead, a reducing atmosphere is created inside of aggregates and several reduction processes will take place:

$$
\begin{aligned}
& 3 \mathrm{Fe}_{2} \mathrm{O}_{3} \rightarrow 2 \mathrm{FeO} \cdot \mathrm{Fe}_{2} \mathrm{O}_{3}+1 / 2 \mathrm{O}_{2} \\
& 3 \mathrm{Fe}_{2} \mathrm{O}_{3}+\mathrm{C} \rightarrow 2 \mathrm{Fe}_{3} \mathrm{O}_{4}+\mathrm{CO} \\
& \mathrm{Fe}_{3} \mathrm{O}_{4}+\mathrm{C} \rightarrow 3 \mathrm{FeO}+\mathrm{CO} \\
& \mathrm{FeO}_{(\mathrm{s})} \rightarrow \mathrm{FeO}_{(\mathrm{l})}
\end{aligned}
$$

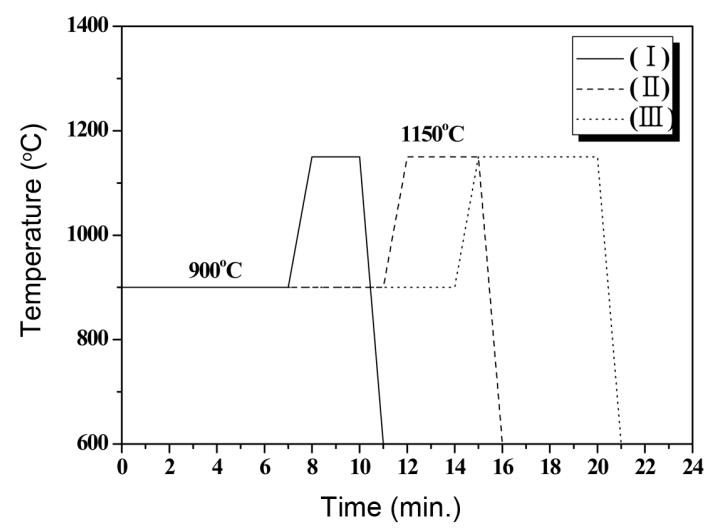

Fig. 1. Schedules of two-step firing. 
It is believed that Reaction (1) (3), which involve in the generation of oxygen and CO are responsible for the bloating action and, thus, the reduction of aggregate bulk density. ${ }^{1)}$ Trapping the generated gases, however, depends on the densification of aggregate surface. At firing temperatures, the surface of aggregates should densify close to a gas-tight state and should be able to expand by the pressure build-up of the bloating gases. Vitreous surface of lowmelting compounds is highly desirable since it can form almost pore-free layer and provide viscous flow as the sintering mechanism so that the surface can flow under the pressure applied by gases. ${ }^{4)}$

Figure 2 shows bulk densities and water absorptions of different raw materials at various temperatures. The sample of $100 \%$ slag started its sintering at $700^{\circ} \mathrm{C}$ and formed

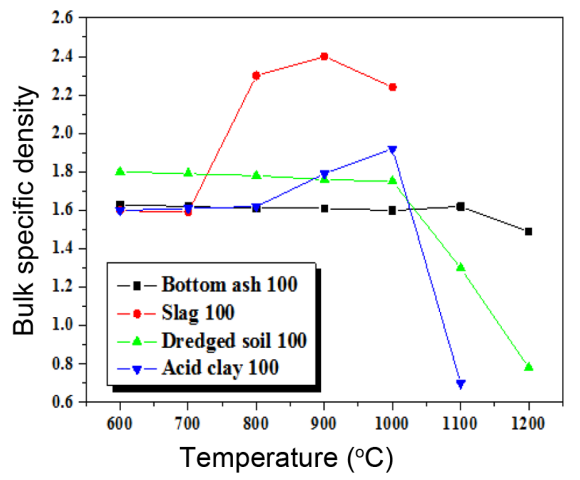

(a) vitreous surface above $900^{\circ} \mathrm{C}$ eliminating all of its pores and reducing the water absorption down to almost zero. In the case of acidic clay, its bulk density decreased drastically in temperature range of $1000 \sim 1100^{\circ} \mathrm{C}$. Its water absorption, however, started to decrease at $700^{\circ} \mathrm{C}$ and gradually reduced down to about $4 \%$. It indicates that acidic clay can form vitreous phase at relatively low temperatures. The increase of water absorption at $1100^{\circ} \mathrm{C}$ seems to be caused by the cracks on the surface as shown in optical images in Fig. 3.

Dredged-soil showed a decreasing tendency of bulk density starting at about $1000^{\circ} \mathrm{C}$ and decreasing water absorption in the temperature range of $1100 \sim 1200^{\circ} \mathrm{C}$ which is indicative of the formation of vitreous phase. In the case of samples of $100 \%$ bottom-ash, they showed some tendency of

Fig. 2. Physical properties of aggregates of warious raw materials with temperature: (a) bulk density and (b) water absorption.

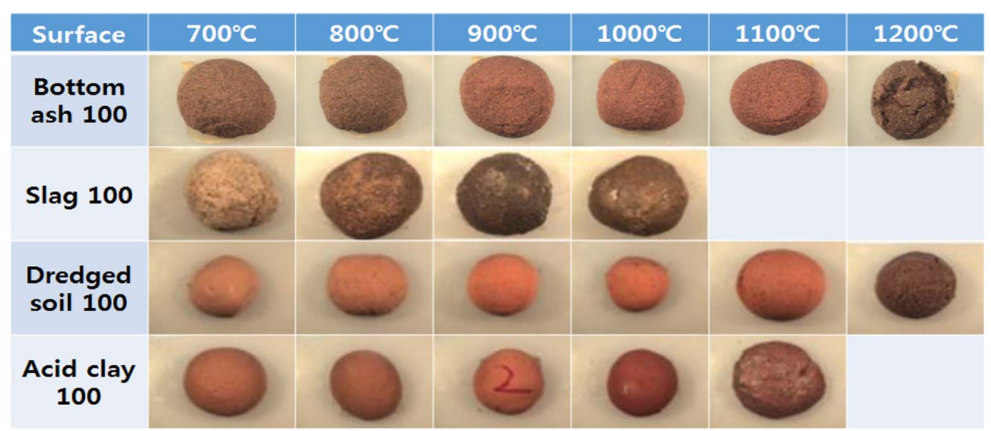

(a)

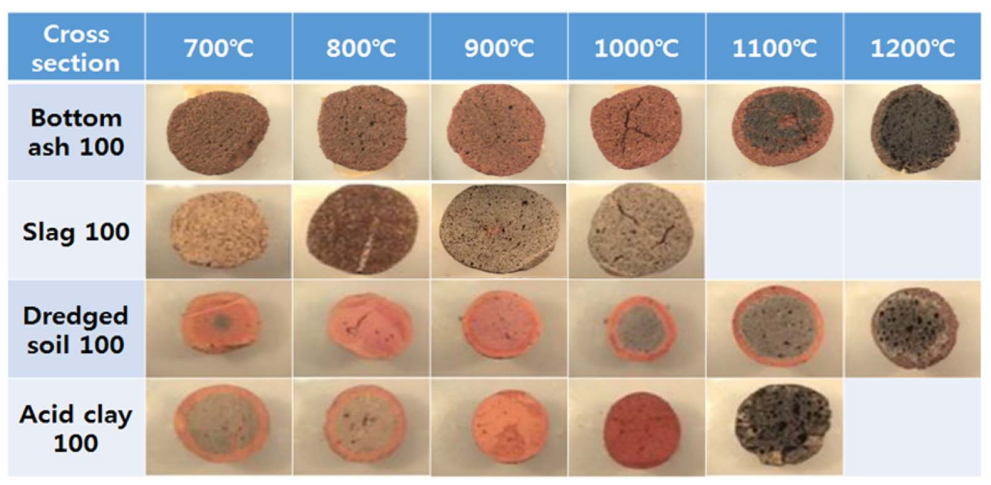

(b)

Fig. 3. Microstructure of various lightweight aggregates with temperature: (a) surface and (b) cross section. 
decreasing bulk density above $1100^{\circ} \mathrm{C}$. But they showed no noticeable bloating probably due to its high refractoriness. They also showed, just like the case of acidic clay, increase in water absorption starting at $1200^{\circ} \mathrm{C}$ with the cracks on the surface.

Surface images in Fig. 3 show that slag forms vitreous phase starting at $900^{\circ} \mathrm{C}$ and tightly encloses the sample with the surface layer. Both surface and cross-sectional surface images of samples with acidic clay show that vitreous phase start to form at $700^{\circ} \mathrm{C}$ and gradually encloses the sample with the surface layer. In the case of dredged-soil, black core starts to form at $1000^{\circ} \mathrm{C}$ and vitreous phase in the temperature range of $1100 \sim 1200^{\circ} \mathrm{C}$.

\subsection{Properties of surface-modified ALWA}

\subsubsection{Direct firing}

As shown in Fig. 2, aggregates of 100\% bottom-ash showed surface vitrification and bloating starting at $1200^{\circ} \mathrm{C}$. On the contrary, all three aggregates of $100 \%$ of slag, dredged-soil, or acidic clay showed surface vitrification starting at much lower temperatures.

Figure 4 shows bulk density and water absorption of aggregates made of bottom-ash with or without coating. Without coating, the sample's behavior is similar to the $100 \%$ bottom-ash as shown in Fig. 2. It shows no densification on surface or bloating up to $1100^{\circ} \mathrm{C}$ maintaining its bulk density of $1.6 \mathrm{~g} / \mathrm{cm}^{3}$. Its bulk density reduced down to $1.2 \mathrm{~g} / \mathrm{cm}^{3}$ at $1200^{\circ} \mathrm{C}$ with surface vitrification and bloating.

All coated aggregates, on the contrary, started the bloating at $1000^{\circ} \mathrm{C}$, and achieved low bulk densities of $1.3 \sim 1.4 \mathrm{~g} /$ $\mathrm{cm}^{3}$ satisfying the KS F 2534 standard for an ALWA. This can be confirmed in cross-sectional images in Fig. 5 that the uncoated aggregates form black core and large pores at $1200^{\circ} \mathrm{C}$, while coated aggregates form pores starting at $1000^{\circ} \mathrm{C}$.

Figure 4(b) shows the contradicting tendency in bulk density and water absorption between uncoated and coated aggregates. This attributes to the fact that the coating layer is applied less densely (Fig. 6). The reason that this tendency is different from the water absorption in Fig. 2(b) is that the surface of uncoated aggregates were under the maximum-temperature exposure for $10 \mathrm{~min}$ by direct firing and, thus, their sintering proceeded more than the case for the coated aggregates.

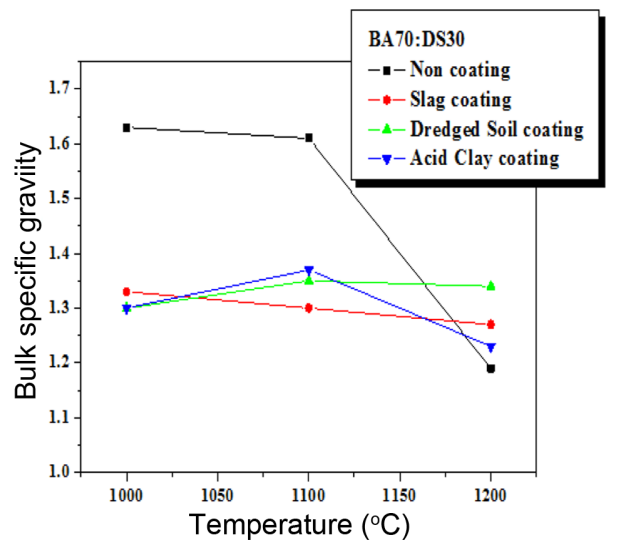

(a)

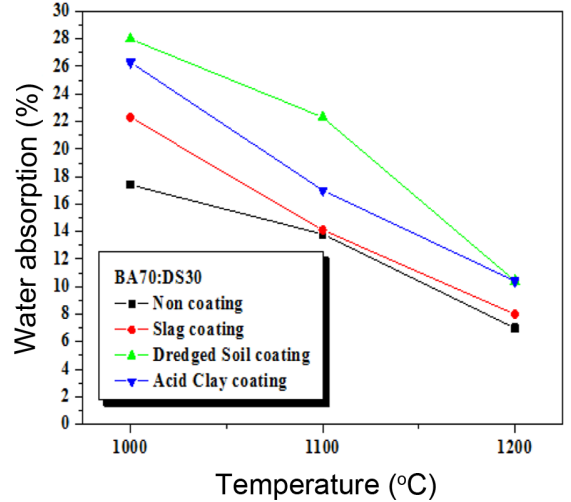

(b)

Fig. 4. Physical properties of direct-fired aggregates with temperature (BA70:DS30).

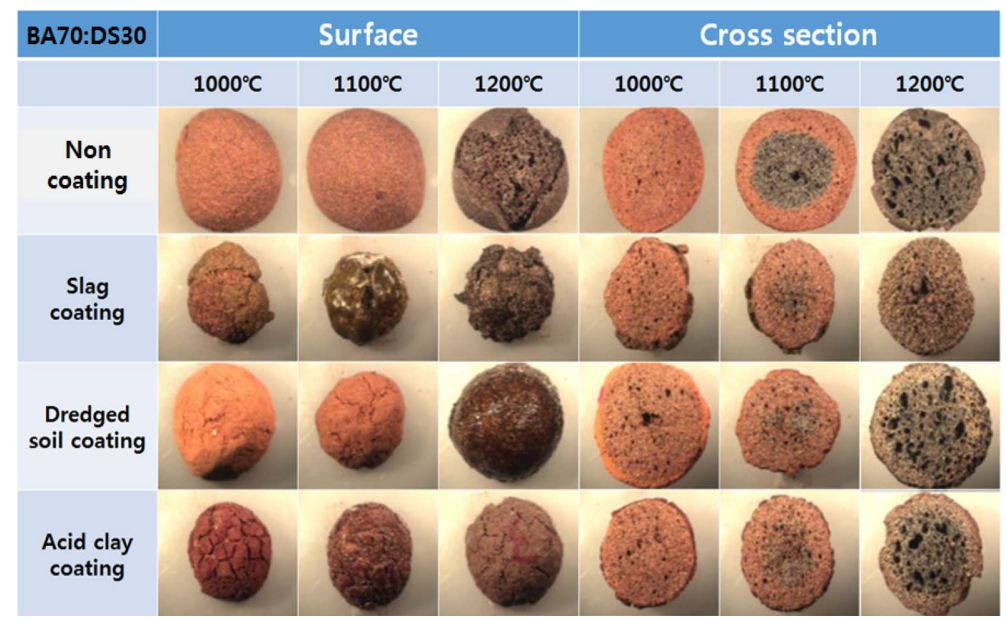

Fig. 5. Microstructure images of direct-fired ALWA with different coatings. 


\subsubsection{Two-step firing}

ALWA are produced by sintering in a rotary kiln in mass production line and the aggregates travel from low-temperature zone to high-temperature zone. Direct firing can describe the bloating behavior but can not properly describe the process of gas trapping. The two-step firing in this study is designed to evaluate both the bloating and gas trapping mechanisms.

As shown in Fig. 4, the coated samples showed surface densification starting at $1000^{\circ} \mathrm{C}$ under direct firing. We, thus, determined the temperature for first step firing at $900^{\circ} \mathrm{C}$. The uncoated aggregates showed bloating at $1100 \sim$ $1200^{\circ} \mathrm{C}$ under the two-step firing. We, thus, set the maximum temperature at $1150^{\circ} \mathrm{C}$ for three different holding times; 10 min (I), 15 min (II), 20 min (III) (Fig. 1).

Figure 6 shows bulk density and water absorption of aggregates made of bottom-ash with coating and fired in two steps in terms of firing temperature and raw materials for coating. Compared to the uncoated samples, the coated samples by two-step firing at $900^{\circ} \mathrm{C}$ for $7 \mathrm{~min}$ plus at $1150^{\circ} \mathrm{C}$ for $3 \mathrm{~min}$ decreased its bulk density by $0.3 \sim 0.4 \mathrm{~g} / \mathrm{cm}^{3}$. All coated aggregates showed lower bulk densities in all temperature range of firing.

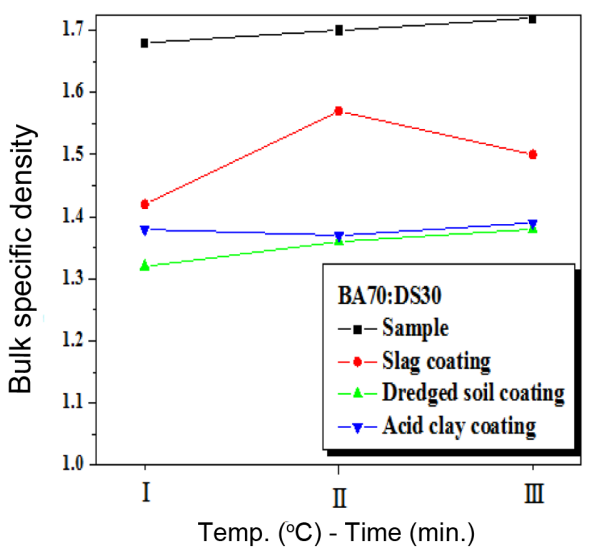

(a)
This indicates that the uncoated aggregates generate more gases at $900^{\circ} \mathrm{C}$ when the holding time is prolonged. The gases, however, escape out of aggregates since the aggregate surface can not keep them due to the lack of densification that leads to no bloating. On the contrary, the coated aggregates are able to achieves densification and vitrification on surface at $1150^{\circ} \mathrm{C}$. The aggregates are eventually able to be bloated and reduce their bulk densities. By comparing between the direct firing and the two-step firing, we confirmed that trapping of bloating gases has more critical effects than its amount generated on the formation of foamed aggregates which leads to the importance of surface densification and vitrification on bloating.

In the case of slag coated aggregates, the generation of foam gases and vitrification proceeded at the same time at $900^{\circ} \mathrm{C}$. Therefore, bloating took place in the case (I), while sintering took place in the cases of (II) and (III) resulting increase in bulk density, which can be considered almost same as the behavior of bulk density in Fig. 2(a).

Figure 7 is optical images of two-step fired specimen of aggregates coated with each raw materials. They revealed many pores generated in the interior of aggregates compared to the uncoated aggregates owing to the low-melting

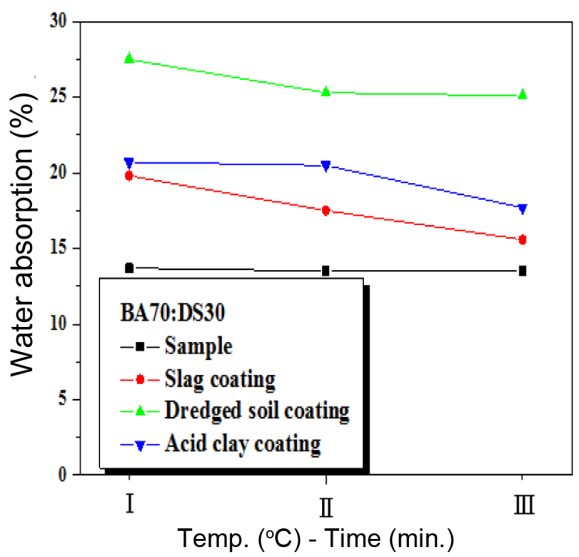

(b)

Fig. 6. Physical properties of two-step fired aggregates with temperature (BA70:DS30): (a) bulk density and (b) water absorption.

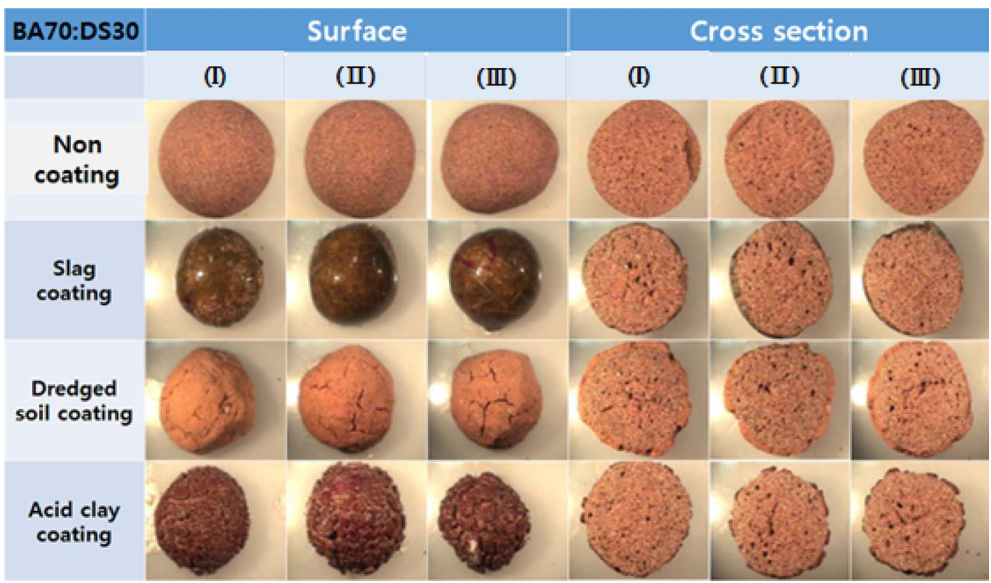

Fig. 7. Microstructure images of two-step fired ALWA with different coatings. 
coat layer. It is confirmed that the decreasing tendency of bulk density is similar to the case of direct firing. By twostep firing, trapping behavior of bloating gases was evaluated. We expect that the results of this study on bloating behavior could be adopted to the rotary kiln in an actual mass production line.

\section{Conclusion}

Based on the firing characteristics of waste materials such as bottom-ash, dredged-soil, slag, and acidic clay, we prepared a mixed sample of bottom-ash and dredged-soil with the wt. ratio of 70:30 and formed into the sphere-like shapes with diameters of about $10 \mathrm{~mm}$ as ALWA. Dredged-soil effectively moderated bottom-ash's lack of plasticity and too-high of refractoriness making the mixture appropriate for an ALWA.

With the coating on surface of aggregate with low-melting oxides, bloating is achieved during the direct firing or the two-step firing. Findings on the mechanism of bloating are:

1) Compared to the uncoated samples, the coated samples with low-melting materials such as slag, dredged-soil, or acidic clay reduces the bulk density of aggregates by $0.3 \sim 0.4 \mathrm{~g} / \mathrm{cm}^{3}$ when they were fired under either schedule at relatively low temperature of $1100^{\circ} \mathrm{C}$.

2) We fired the aggregates directly or in two steps to modulate the rate of the gas generation and its escape out of aggregates along with the densification and vitrification rates on surface. We concluded that the trapping of bloating gases has more critical effects than its amount generated on the formation of bloated aggregates.

3) Both direct firing or a two-step firing show same tendency of reducing the bulk density of aggregates and, thus, give a promising aspect when these procedures are implemented under the conditions of mass production.

\section{Acknowledgments}

This work was supported by Kyonggi University Research Grant 2012.

\section{REFERENCES}

1. K. G. Lee, "Bloating Mechanism for Coal Ash with Iron Oxide," J. Korean Assoc. Cryst. Growth. Technol., 24 77-83 (2014).

2. S. H. Kang, K. G. Lee, Y. T. Kim, and S. G. Kang, "Effects of Chemicophysical Properties of Carbon on Bloating Characteristics of Artificial Lightweight Aggregates Using Coal Ash," Adv. in Sinter. Sci. Technol. II, 232 35-42 (2011).

3. C.-C. Tsai, K.-S. Wang, and I.-J. Chiou, "Effect of $\mathrm{SiO}_{2}$ $\mathrm{Al}_{2} \mathrm{O}_{3}$-Flux Ratio Change on the Bloating Characteristics of Lightweight Aggregate Material Produced from Recycled Sewage Sludge," J. Hazard. Mater, 134 [1-3] 87-93 (2006).

4. S. H. Kang and K. G. Lee, "Bloating Mechanism of Artificial Lightweight Aggregate for Recycling the Waste Glass(in Korean)," J. Korean Ceram. Soc., 47 [5] 445-49 (2010).

5. S. J. Lee and T. Y. Lee, "Field Tests for the Application of Bottom-ash and Shred Tire as Fill Materials," J. Korean Geo-Environ. Soc., 14 [10] 29-37 (2013).

6. K. D. Kim, J. H. Kim, Y. T. Kim, S. G. Kang, and K. G. Lee "Production of Lightweight Aggregates Using Power Plant Reclaimed Ash(in Korean)," J. Korean Ceram. Soc., 47 [6] 583-89 (2010).

7. D. S. Kim, C. K. Lee, and J. H. Park, "Sintering Properties of Artificial Lightweight Aggregate Prepared from Coal Ash and Limestone(in Korean)," J. Korean Ceram. Soc., 39 [3] 259-64 (2002).

8. C. M. Riley, "Relation of Chemical Properties to the Bloating of Clay,” J. Am. Ceram. Soc., 34 [4] 121-28 (1951).

9. P. S. Nicholson, "Kinetics of Oxidation of Natural Organic Materials in Clays," J. Am. Ceram. Soc., 53 [3] 154-58 (1970).

10. V. A. Abdakhimov and E. C. Abdrakhimova, "Formation of the Black Core in High-speed Firing of Floor Tiles," Glass Ceram., 56 [7-8] 263-65 (1996).

11. W. E. Brownell, "Black Coring in Structural Clay Products," J. Am. Ceram. Soc., 40 [6] 179-87 (1957).

12. M. A. Kang, S. G. Kang, K. G. Lee, and Y. T. Kim, "Fabrication of Artificial Light-weight Aggregates of Uniform Bloating Properties Using a Temperature-raising Sintering Method(in Korean)," J. Korean Ceram. Soc., 49 [2] 161-66 (2012). 